\title{
Not gendered... but different from each other? A structural equation model for explaining risky road behaviors of female and male pedestrians
}

\author{
Sergio A. Useche ${ }^{\mathrm{a}, \mathrm{b}, *}$, Amin Mohamadi Hezaveh ${ }^{\mathrm{c}}$, Francisco J. Llamazares ${ }^{\mathrm{d}}$, \\ Christopher Cherry ${ }^{\mathrm{c}}$ \\ a Department of Personality, Evaluation and Psychological Treatment, Faculty of Psychology, University of Valencia, Valencia, 46022, Spain \\ ${ }^{\mathrm{b}}$ INTRAS (Research Institute on Traffic and Road Safety), University of Valencia, Valencia, 46022, Spain \\ ${ }^{\mathrm{c}}$ Civil and Environmental Engineering, University of Tennessee, Knoxville, TN 37996-2313, United States \\ d Department of Technology, ESIC Business and Marketing School, Spain
}

\section{A R T I C L E I N F O}

\section{Keywords:}

Pedestrians

Gender

Risky behaviors

Errors

Violations

Differences

\begin{abstract}
A B S T R A C T
As alternative transportation is getting more and more fashionable, and more people worldwide are "shifting" to walking trips, even for their daily commuting, traffic crashes suffered by pedestrians are still a great concern for road safety and public health researchers and practitioners. In this regard, risky or "aberrant" road behaviors have emerged, during the last few years, as a key issue to be considered for crash prevention. Nevertheless, the idea of a "generic pedestrian" is getting re-evaluated, and analyzing key features, such as gender, seems to be crucial for understanding pedestrians' performance and safety outcomes.

Objective: The objective of this study was to examine the effect of gender on pedestrians' both deliberate (traffic violations) and undeliberate (errors) risky walking behaviors, considering a set of theoretically based demographic and psychosocial variables as their potential predictors.

Method: For this cross-sectional study, data from 1070 Spanish pedestrians (60\% females and $40 \%$ males, aged between 16 and 79) from the 17 regions of Spain, responding to an electronic questionnaire, were analyzed through a multi-group structural equation modeling (MGSEM) approach.

Results: Although age, handheld device-interaction, and sensation-seeking seem to have a similar effect on the errors and violations reported by both genders (similarities), factors such as risk perception, educational level and the misbehaviors observed in other road users are significant predictors only in the case of male pedestrians. On the other hand, road distractions have been shown to play a significant role in females' errors and violations, while males' road distractions seem to only affect their involuntary risky behaviors.

Conclusion: The findings of this study support the influence of gender in the statistical explanation of both deliberate and undeliberate walking risky road behaviors, also depicting the differential role of certain demographic and psychosocial factors when we compare male and female pedestrians.
\end{abstract}

\section{Introduction}

During the last decades, when transportation dynamics have been experiencing several transformations, walking has been systematically promoted as a cheap (Audrey et al., 2014), sustainable (Grant, Machaczek, Pollard \& Allmark) and healthy (Hanson and Jones, 2015) means for performing short and mid-length trips - or parts of them - for daily commuting (Barr et al., 2019; Oja et al., 1998). Indeed, many organizational and educational stakeholders have been recently promoting "active commuting" (i.e., using non-motorized transportation means such as walking or cycling) for commuting trips, as a way of encouraging their employees/students to improve their lifestyle and health outcomes (Barranco-Ruiz et al., 2019; Page and Nilsson, 2017; Yang et al., 2012). Furthermore, regular walking not only enhances a healthier lifestyle and reduces the likelihood to suffer many mental issues such as stress, anxiety, depression and cognitive impairments

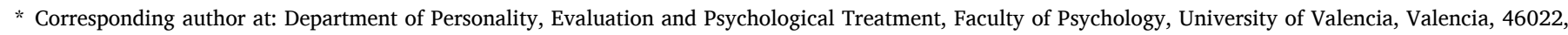
Spain.

E-mail addresses: sergio.useche@uv.es (S.A. Useche), amohamad@vols.utk.edu (A.M. Hezaveh), javier.1lamazares@esic.edu (F.J. Llamazares), cherry@utk.edu (C. Cherry).
} 
(Edwards \& Loprinzi, 2018; Anderson and Shivakumar, 2013; Marselle et al., 2013), but also it helps to prevent physical conditions such as excessive weight (Hanson and Jones, 2015), Type II Diabetes (Colberg et al., 2010), hypertension and other cardiovascular diseases (Zhao et al., 2015; Warburton et al., 2006).

However, and as it happens for all transportation means, walking also implies certain risks that, depending on both the context and key pedestrian's individual features, may affect their safety and welfare. Accross the literature, it is easily noticeable that traffic crashes are -although not the only- the most widespread concern for this population, since the injuries and fatalities they suffer still represent a considerably high burden for community health (Khan et al., 2020). On the other hand, many efforts are being made for targeting, studying, and taking actions towards the reduction of pedestrians' crashes around the world. Apart from built environment characteristics, human factors are also being highly considered for it. For instance, road users' sociodemographic features and risky behaviors, e.g. walking distracted, under the influence of alcohol, or running red traffic lights, seem to be relevant contributors to both the frequency and severity of these causalities (Hezaveh and Cherry, 2018; Hezaveh et al., 2018a; Onieva-García et al., 2016; Zhu et al., 2013).

\subsection{Errors and violations as risky behaviors: the "will" matters}

Although one can mistakenly generalize when discussing the prevalence, taxonomy, and crash-likelihood of many possible aberrant behaviors, it is worth saying that not all of them are, for example, intentionally planned by users; therefore, a categorical differentiation is needed in this regard. Recent studies have suggested that the distinction between deliberate and undeliberate (involuntary) risky behaviors is necessary to understand some key differences among behavioral contributors involved in pedestrian crashes (Useche et al., 2020; Deb et al., 2017), as it has been traditionally done in the case of other types of road user, such as drivers (Reason et al., 1990), motorcyclist (Elliott et al., 2007) and cyclists (Hezaveh et al., 2018b; Useche et al., 2018a). Hence, this study follows a differentiative approach to risky behaviors, i.e., traffic violations (that can be understood as "deliberate" risky behaviors) and errors (recognized as non-deliberate but still risky behaviors on the road), both of them equally considered problematic issues for road users' safety and welfare (Hezaveh et al., 2018b; Reason et al., 1990).

Also, there are different factors that, supported by scientific literature, have shown to influence the likelihood to perform risky road behaviors while walking. Some of them, seeming to have a crucial role in current transportation dynamics, were addressed in the present study, as follows: first, personality traits - that are associated with risk perception and acceptance, -may influence the performance of aberrant behaviors. Among them, the role of "sensation seeking" is remarkable (Zheng et al., 2017; Freeman and Rakotonirainy, 2015). It is defined as the seeking of intense, new stimuli at the often substantial risk of financial, social, legal, and/or physical costs (Miller and Quick, 2010; Zuckerman, 1994).

Second, the past few years have seen a high problematization of the influence of engaging with cellphones and "connected" handheld device on the risky behavior of many types of road users, including pedestrians, who are considered a critical risk group (Young et al., 2020; Oviedo-Trespalacios et al., 2019). These studies support the idea that higher involvement in $\mathrm{ICTs}^{1}$, that is becoming more frequent and intense among young and adult users may impair both their road behaviors and walking performance, enhancing, for instance, road distractions (Oviedo-Trespalacios et al., 2019).

Finally, some studies performed with non-motorized users in the last years have documented the importance of risk perception for preventing

\footnotetext{
${ }^{1}$ ICTs is an acronym for both Information and Communication Technologies and Internet Connected Technologies, that are often interchangeably used in Europe and many English-speaking countries.
}

aberrant road behaviors, as well as the existence of key differences between users, as it happens (for instance) between male and female road users (Useche et al., 2018b; Barić et al., 2018; Yu et al., 2020).

\subsection{A short review of gender differences in walking behavior}

To be specific, gender differences are the main focus of this paper, so it is worth introducing a summary of empirically-based gender differences already addressed in the literature: they allowed us to structure our hypothesis, according to which the risky road behaviors of pedestrians may be differentially influenced between genders.

First of all, pedestrians of different age groups have shown significant differences in both deliberate and undeliberate aberrant road behaviors. For instance, studies such as the one performed by Wang et al. (2018) with children and pre-adolescents discuss how, from early ages, boys (males) and girls (females) already exhibit different characteristics in their walking behaviors; specifically, boys show a significantly higher frequency in playing on the sidewalk - next to the vehicle lanes, while girls are more prone to walking side-by-side with partners. Furthermore, during the last decades Assailly (1997 \& 1993) has showed how, in every European country, boys have higher pedestrian accident rates than girls, typically being twice as likely as girls to be injured, due to both their higher risk exposure and road behaviors that seem to work considerably "differently" than the one observable among girls. For instance, young males are often more impulsive and remain less attentive to traffic context features (Posner et al., 2002; Assailly, 1993). Also, both young and adult male pedestrians have consistently shown considerably lesser risk perception levels than their female counterparts (Rankavat and Tiwari, 2019 \& 2016; Hashemiparast et al., 2017; Cordellieri et al., 2016).

Regarding further life stages, behaviorally-based empirical researches carried out with adult pedestrians addressing key safety-related road behaviors have shown that, for instance: rule-breaking is considerably more frequent among males than females (Rosenbloom et al., 2004; Yagil, 2000 \& 1998); male pedestrians have shown higher intentions to perform risky road behaviors, especially younger and non-driver ones (Holland and Hill, 2007); at crossings, that are frequently critical pre-crash scenarios, rule compliance is significantly lower among male pedestrians, who, at the same time, tend to suffer more crashes (Poó et al., 2018; Ferenchack, 2016; Tom and Granié, 2011).

\subsection{Objectives and hypotheses}

The objective of this study was to examine the effect of gender on pedestrians' deliberate (traffic violations) and undeliberate (errors) risky road behaviors, considering a set of theoretically based demographic and psychosocial variables as their potential predictors.

Regarding the hypotheses of the study, and bearing in mind previous research supporting the influence of the study variables on the road behavior of pedestrians, we expected to find: 1) that pedestrians' demographic and psychosocial variables would significantly explain the rates of their self-reported involvement in risky behaviors on the road (errors and traffic violations), but 2) that these variables would have a differential influence on risky behaviors when considering gender as an analytical category.

\section{Methods and materials}

\subsection{Sample}

For this cross-sectional study, the data were collected from a full sample of $n=1070$ pedestrians from the 17 autonomous communities (regions) of Spain: 642 (60\%) participants were females and 428 (40\%) males.

As for the educational level of the participants, approximately half of 
them (44.6\%) had an undergraduate degree (ongoing or already completed), and $9.7 \%$ a post-graduate degree. $17.6 \%$ of them had received a technical training (more advanced than a high school diploma, but lower than university degrees); $21.5 \%$ had a high school degree, and a remaining $6.6 \%$ had a maximum level of primary studies. They were aged between 16 (minimum) and 79 (maximum), with an average of $M=30.8$ ( $S D=12.9$ ) years. As for walking patterns, this information on the sample is presented in Table 1.

\subsection{Study design and procedure}

For this cross-sectional research, participants (invited to partake through verified inter-institutional mailing lists of Spanish-speaking subjects, shared among various universities and research centers) completed an online form that was individually sent through electronic (i.e., e-mail and social network) invitation. The questionnaire was designed and applied to ensure the anonymity of its participants.

Before starting the e-form completion (and to prevent participants from providing biased responses), we emphasized the existing data protection laws and the fact that (i) the questionnaire was anonymous, and (ii) the collected information would be strictly used for collective research and divulgation only. The importance of answering honestly to all questions was highlighted, as well as the non-existence of wrong or right answers, positively encouraging participants to give honest answers, from which the quality of the study's results depends.

As selection/exclusion criteria, potential participants (those subjects accessing the online form) were asked to complete the questionnaire only if they regularly performed walking trips (it was suggested, as a guideline, "if you walk with certain regularity, at least once per week"), and did not suffer from substantial health (whether physical or mental) conditions, which could potentially impair their walking performance. The informed consent form was checked and accepted by participants before they participated in the survey, that (discarding 11 incomplete, wrongly, or partially completed questionnaires) was fully completed by 1070 participants. The response rate was approximately $53 \%$, bearing in mind that approximately \pm 2000 invitations to fill the electronic form were initially delivered.

\subsection{Description of the questionnaire}

The questionnaire was administrated in Spanish and consisted of three sections:

The first part inquired about individual and demographic variables, such as age, gender, educational level, and occupation; it also contained

Table 1

Descriptive data on the walking patterns of the study sample.

\begin{tabular}{llll}
\hline Feature & Category & Frequency & Percentage \\
\hline & $\begin{array}{l}\text { Daily commuting } \\
\text { Exercise or fitness }\end{array}$ & 414 & $38.7 \%$ \\
& Housework tasks (e.g., go & 106 & $9.9 \%$ \\
shopping, picking up & 154 & $14.4 \%$ \\
Main reason for & children...) & & \\
walking trips & Short trip to a specific place in & & \\
& the city & 227 & $21.2 \%$ \\
& Leisure ("going for a walk") & 132 & $12.3 \%$ \\
& Part of their job tasks & 37 & $3.5 \%$ \\
& $<1 \mathrm{~h}$ & 49 & $4.6 \%$ \\
Hours spent walking & $1-5 \mathrm{~h}$ & 403 & $37.7 \%$ \\
in a week & $6-10 \mathrm{~h}$ & 380 & $35.5 \%$ \\
& $11-15 \mathrm{~h}$ & 104 & $9.7 \%$ \\
& $16-20 \mathrm{~h}$ & 45 & $4.2 \%$ \\
& $>20 \mathrm{~h}$ & 89 & $8.3 \%$ \\
Length of their most & $0-15$ min & 305 & $28.5 \%$ \\
common walking & $31-45$ min & 486 & $45.4 \%$ \\
trip & $46-60 \mathrm{~min}$ & 134 & $12.5 \%$ \\
& $>60 \mathrm{~min}$ & 91 & $8.5 \%$ \\
\hline
\end{tabular}

a brief questionnaire about walking habits, including the number of trips per week (frequency), their average duration, and main reasons for performing walking trips.

As for the second part, self-reported risky walking behaviors were assessed using the two risky behavior subscales included in the validated version of the Walking Behavior Questionnaire (WBQ; Useche et al., 2020), a self-report instrument specifically designed to measure high-risk walking behaviors (errors and violations) within the specific context of pedestrian circulation. These Likert scales are originally composed of 14 items for Traffic Violations (deliberate risky behaviors; $\alpha=0.890$; example item: "despite being relatively close to the crosswalk, crossing the road among cars") and 16 items for Errors (undeliberate risky behaviors; $\alpha=0.868$; example item: "realizing that you have just crossed at a traffic light that was not green"). The entire questionnaire uses a 5-level frequency-based response scale: $0=$ never; 1 =hardly ever; $2=$ sometimes; $3=$ frequently; $4=$ almost always.

In the third part of the questionnaire, the road-risk perception was measured through the Risk Perception Subscale (RPRS; Useche et al., 2018b), that is a 7-item Likert scale in which the degree of risk perceived in objective risk factors is assessed, with a 0 (no risk perceived) to 4 (highest risk perceived) hierarchy ( $\alpha=0.851$ ). Road distractions were evaluated through the Road Distractions Inventory (RDI; Useche et al., 2018b), an 8-item dichotomous scale aimed at presenting different potential distractors commonly present within the road scenario ( $\alpha=0.652$; example potential distractor: "the obstacles in the way"). Sensation seeking was measured through the Brief Sensation Seeking Scale (BSSS; Stephenson et al., 2007), an 8-item Likert questionnaire assessing the individuals' need for novel, complex and intense experiences (i.e., sensation-seeking personality trait), with a 0 (strongly disagree) to 4 (strongly agree) scale ( $\alpha=0.875$ ).

Finally, two supplementary indicators were used to assess: (i) the overall degree of interaction of participants with Information and Communication Technologies (ICTs; such as mobile phones, tablets, navigators and other portable internet-connected devices; Montoro et al., 2019) in a single-item scale ranging from 1 (very scarce interaction) and 5 (very high interaction). Observed road misbehaviors were measured through a 4-item Likert short questionnaire assessing how frequently pedestrians observe other road users committing traffic-rule violations ( $\alpha=0.890$; road users: "other pedestrians," "bicycle riders," "kick-scooter riders," and "motor-vehicle drivers"), in a scale ranging from 0 (never/almost never) to 4 (always/almost always).

\subsection{Ethics}

To carry out this study, the Social Science in Health Research Ethics Committee of the University of Valencia was consulted, certifying that our research responded to the general ethical principles and that it complied with the Declaration of Helsinki (IRB approval number H1535548125595). Furthermore, an Informed Consent Statement containing ethical principles and data treatment details was used, explaining the objective of the study, the mean duration of the survey, the treatment of personal data, and the voluntary participation, and it was read by participants before they responded to the questionnaire. Personal and/or confidential data were not used, and the participation was anonymous, thus implying no potential risks for the integrity of our partakers.

\subsection{Statistical analysis (data processing)}

After data curation, basic descriptive analyses were performed to obtain scores for the Walking Behavior Questionnaire (WBQ), and descriptive statistics (mean, standard deviations, standardized errors, and $95 \%$ CIs (confidence intervals) were calculated. Once the basic parameters were tested, gander-based One-Way ANOVA analyses were performed to compare the mean scores of the continuous variables, in order to explore potential significant differences across females and 
males in terms of the study variables.

The study data were analyzed through a SEM (Structural Equation Modeling) approach that, given the available theoretical and empirical background, involved both a CFA or Confirmatory Factor Analysis-based measurement model and a structural model, that is similar to a multiple regression analysis (Chen and Donmez, 2016). The measurement model can be defined as the assessment of the relationships between the latent variables and the items/components used to measure them. In this case, the latent variables were: observed misbehaviors, road distractions, sensation seeking, risk perception, traffic violations and errors.

While their validity was tested by means of factor loadings $(\lambda s)$ indicating their relatipnship to the underlying factor, the reliability of the latent variables was assessed through Cronbach's Aplhas ( $\alpha$ ), that can be considered as acceptable when $>.60$. However, and considering that -although widely used- Alpha coefficient has been criticized as a single indicator (Morera and Stokes, 2016; Hökerberg et al., 2014), Composite Reliability Indexes (CRIs; that can be considered as acceptable indicators when $>0.70$, suggesting a good internal consistency), were also used to assess the internal reliability of the scales (Hökerberg et al., 2014). The cutoff criteria for item factor loadings was set at 0.30 , as suggested by specialized sources, in view that the study used a considerably large sample size ( $n>300$ subjects), there were previous evidences on the scales used and complementary indexes for corroborating their validity and reliability were also in cluded in the study (Stevens, 2002; Politi et al., 1994).

As for the structural modelm used to assess the relationships among measured variables based on the study hypotheses, the multivariate relationships between female and male pedestrians' demographic/psychosocial factors and deliberate (Traffic Violations; Model A) and undeliberate risky behaviors (Errors; Model $B$ ) were tested using multigroup analyses, through MGSEM (Multi-Group Structural Equation Models). This is statistically more accurate than separately testing genders as separate populations since it considers the full sample parameters for fitting the models, drawing covariances between exogenous factor errors and controlling by walking frequency and trip length, to minimize the potential impact of risk exposure in the model's results. Also, and although beta coefficients are standardized and can be interpreted as controlling for the effects of other predictors within the model, the errors of highly-correlated independent (exogenous) variables were covaried, in order to account for the systematic statistical correlations without implying causal relationships. Given that some of the data used were ordinal (as usually happens with variables such as educational level and Likert-based scales), and that the assumption of multivariate normality was not met, Weighted Least Square Mean and Variance corrected (WLSMV) estimations were used, as suggested by Finney and DiStefano (2013). In brief, WLSMV estimation methods entail several advantages over Maximum Likelihood estimations, especially if it is considered the fact that categorical variables (e.g. educational level) were specified in the SEM model, making the model estimations more robust and reducing biased significance outputs (Beauducel and Herzberg, 2006). The significance criteria were differentially established for $p<0.05, p<0.01$, and $p<0.001$.

The goodness-of-fit of models A and B were evaluated using an extensive set of indices from various families endorsed by the specialized literature (Kline, 2011; Hu and Bentler, 1999): Chi-square $\left(\chi^{2}\right)$, minimum discrepancy ratio (CMIN/df, that is the ratio between the Chi-square and the degrees of freedom used); Confirmatory Fit Index (CFI), Normed Fit Index (NFI), Tucker-Lewis Index (TLI), Incremental Fit Index (IFI) and Root Mean Square Error of Approximation (RMSEA) with $90 \%$ Confidence Intervals. Goodness-of-fit was decided based on the cut-off criteria expanded in the literature: RMSEA $<0.08$, incremental indices (CFI/NFI/TLI/IFI) $>0.90$, and a CMIN/df ratio $<5.0$ are indicative of an adequate model fit (Miles and Shevlin, 2007; Marsh et al., 2004).

All statistical analyses were performed using @IBM SPSS (Statistical Package for Social Sciences), version 26.0, and CIBM SPSS AMOS, version 26.0 -used explicitly for multi-group structural equation modeling.

\section{Results}

\subsection{Descriptive outcomes}

The descriptive statistics are presented in Table 2. Overall, not many significant differences were found between female and male pedestrians concerning most of the study variables; for instance, mean values of age, risk perception, sensation-seeking trait, and traffic violations were statistically equivalent. Nevertheless, and concerning significant $(\mathrm{p}<.05)$ mean differences, it was found that female pedestrians presented a significantly higher mean score for road distractions $(M=4.90$; $S D=1.93$ for women, versus $M=4.58 ; S D=2.02$ for men), their overall level of interaction with information and communication technologies or ICTs $(M=1.95 ; S D=1.01$ for females, and $M=1.74 ; S D=0.94$ for males), and undeliberate risky walking behaviors, or errors $(M=0.75$; $S D=0.54$ for women, and $M=0.69 ; S D=0.55$ for men). Further information on the scales used for measuring each variable is available in section "2.3 Description of the questionnaire".

\subsection{The measurement model}

The measurement model tests how well a set of measured items or variables fit together and are representative of a construct of interest. As previously described, for each of the psychosocial latent variables included in the study (i.e., observed misbehaviors, road distractions, sensation seeking, risk perception, traffic violations and errors), and apart from the overall descriptives presented in Table 2, a set of validity and reliability indicators were obtained, as shown in Table 3. The validity of the measures was assessed through standardized factor loadings ( $\lambda$ coefficients) and reliability and consistency of each latent variable was assessed using both Composite Reliability Indexes (CRIs) and Cronbach's Alpha coefficients $(\alpha)$.

All latent variables had adequate internal reliability and consistency indexes, with (i) acceptable to good Cronbach's Alphas between 0.652 and .890 (Morera and Stokes, 2016), and (ii) adequate Composite Reliability Indexes (CRIs) ranging from 0.890 and .989 (Hökerberg et al., 2014). Secondly, standardized factor loadings were $\lambda>0.30$, significant at the cut-off point $p<.001$ for all the latent variables used. Table 3 also shows variable-component' descriptives, in accordance to the structure of the scales used (please see section "2.3 Description of the questionnaire" for further information).

\subsection{The structural models}

\subsubsection{Model A: effect of gender on deliberate risky behaviors while walking (traffic violations)}

Based on the aforementioned theoretical points (please see Introduction), the effect of gender on self-reported deliberate risky behaviors, i.e., traffic violations of pedestrians, was examined using a multi-group SEM (Structural Equation Modeling) approach, that is substantially different from including a "dummy" category (e.g., "being a male") as a study variable within the structural model -that could be methodologically limited in this case, and allows for a different assessment of the effect of the exogenous factors on the dependent variable for each group. In this sense, data were split into two gender-based groups (reference categories): a group of $642(60 \%)$ female, and a group of 428 (40\%) male pedestrians, both of them with acceptable sample size and proportionality for the comparative exploration. Using the SPSS AMOS multi-group (MGSEM) analysis, the hypothesized structural model was adjusted to fit the data according to gender, but at the same time, considering the parameters of the full sample.

The resulting Structural Equation Model, simultaneously fitted for both gender groups or categories $\left(x^{2}(18)=70.444, p<.001 ; \mathrm{CMIN} / \mathrm{df}\right.$ 
Table 2

Descriptive statistics and mean comparisons between genders.

\begin{tabular}{|c|c|c|c|c|c|c|c|c|c|}
\hline \multirow[t]{2}{*}{ Study Variable } & \multirow[t]{2}{*}{ Factor } & \multirow[t]{2}{*}{$\mathrm{N}$} & \multirow[t]{2}{*}{$M^{1}$} & \multirow[t]{2}{*}{$\mathrm{SD}^{2}$} & \multirow[t]{2}{*}{$\mathrm{SE}^{3}$} & \multicolumn{2}{|c|}{$95 \% \mathrm{CI}^{4}$} & \multicolumn{2}{|l|}{ ANOVA } \\
\hline & & & & & & Lower & Upper & $\mathrm{F}_{(1,1068)}$ & Sig. \\
\hline \multirow{4}{*}{ Age } & Female & 642 & 30.72 & 12.91 & .51 & 29.72 & 31.73 & \multirow{4}{*}{.113} & \multirow{3}{*}{$.737^{(\mathrm{N} / \mathrm{s})}$} \\
\hline & Male & 428 & 31.00 & 12.96 & .63 & 29.76 & 32.23 & & \\
\hline & Total & 1070 & 30.83 & 12.92 & .40 & 30.06 & 31.61 & & \\
\hline & Female & 642 & 2.07 & .83 & .03 & 2.01 & 2.14 & & \\
\hline \multirow[t]{3}{*}{ Observed Misbehaviors } & Male & 428 & 2.14 & .76 & .04 & 2.07 & 2.22 & \multirow[t]{3}{*}{1.379} & \multirow[t]{3}{*}{$.241^{(\mathrm{N} / \mathrm{S})}$} \\
\hline & Total & 1070 & 2.10 & .80 & .02 & 2.05 & 2.15 & & \\
\hline & Female & 642 & 4.90 & 1.93 & .08 & 4.75 & 5.05 & & \\
\hline \multirow[t]{3}{*}{ Road Distractions $^{5}$} & Male & 428 & 4.58 & 2.02 & .10 & 4.39 & 4.78 & \multirow[t]{3}{*}{6.498} & \multirow[t]{3}{*}{$.011^{(*)}$} \\
\hline & Total & 1070 & 4.77 & 1.97 & .06 & 4.65 & 4.89 & & \\
\hline & Female & 642 & 1.95 & 1.01 & .04 & 1.87 & 2.02 & & \\
\hline \multirow[t]{3}{*}{ Interaction with ITCs } & Male & 428 & 1.74 & .94 & .05 & 1.65 & 1.83 & \multirow[t]{3}{*}{10.722} & \multirow[t]{3}{*}{$.001^{(* *)}$} \\
\hline & Total & 1070 & 1.87 & .99 & .03 & 1.81 & 1.92 & & \\
\hline & Female & 642 & 1.07 & .99 & .04 & .99 & 1.14 & & \\
\hline \multirow[t]{3}{*}{ Sensation Seeking } & Male & 428 & 1.05 & 1.00 & .05 & .95 & 1.14 & \multirow[t]{3}{*}{.069} & \multirow[t]{3}{*}{$.792^{(\mathrm{N} / \mathrm{S})}$} \\
\hline & Total & 1070 & 1.06 & 1.00 & .03 & 1.00 & 1.12 & & \\
\hline & Female & 642 & 2.59 & .86 & .03 & 2.53 & 2.66 & & \\
\hline \multirow[t]{3}{*}{ Risk Perception } & Male & 428 & 2.64 & .88 & .04 & 2.55 & 2.72 & \multirow[t]{3}{*}{.572} & \multirow[t]{3}{*}{$.450^{(\mathrm{N} / \mathrm{S})}$} \\
\hline & Total & 1070 & 2.61 & .87 & .03 & 2.56 & 2.66 & & \\
\hline & Female & 642 & 1.57 & .69 & .03 & 1.52 & 1.62 & & \\
\hline \multirow[t]{3}{*}{ Traffic Violations } & Male & 428 & 1.59 & .68 & .03 & 1.53 & 1.66 & \multirow[t]{3}{*}{.306} & \multirow[t]{3}{*}{$.580^{(\mathrm{N} / \mathrm{S})}$} \\
\hline & Total & 1070 & 1.58 & .69 & .02 & 1.54 & 1.62 & & \\
\hline & Female & 642 & .75 & .54 & .02 & .71 & .79 & & \\
\hline \multirow[t]{2}{*}{ Errors } & Male & 428 & .69 & .55 & .03 & .63 & .74 & \multirow[t]{2}{*}{3.812} & $.047^{(*)}$ \\
\hline & Total & 1070 & .72 & .54 & .02 & .69 & .76 & & \\
\hline
\end{tabular}

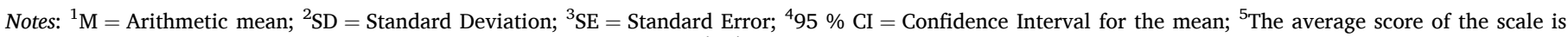
summative; $* *$ Significant at level $p<.01 ; *$ Significant at level $p<.05 ;{ }^{(\mathrm{N} / \mathrm{S})}$ Non-significant difference.

$=3.914 ; \mathrm{NFI}=.970 ; \mathrm{CFI}=.977 ; \mathrm{TLI}=.928 ; \mathrm{IFI}=.977 ; \mathrm{RMSEA}=.052$, IC $90 \%$ [.040-.065]), is presented through two different graphical models in Fig. 1. In this regard, the impact of exogenous variables on traffic violations performed by pedestrians showed differential trends in male and female individuals. The standardized path coefficients (see Table 4 and values next to solid lines in Fig. 1) of the model suggest that, in the case of female pedestrians, there is a negative association between age ( $\beta=-0.164 ; p<.001)$ and traffic violations (endogenous variable). On the other hand, positive relationships were found between road distractions $(\beta=.075 ; p<.001)$, interaction with ICTs $(\beta=0.602 ; p<$ $.001)$, sensation seeking $(\beta=0.283 ; p<.001)$ and these deliberate risky behaviors.

In the case of males, and compared to the structure of the significant model found for women, the exogenous variables presenting a significant association with traffic violations substantially differ, although some communalities are kept. In brief (similarities), pedestrians' age $(\beta=$ $-0.153 ; p<.001)$, their level of interaction with ICTs $(\beta=0.555 ; p<$ $.001)$ and the sensation seeking trait $(\beta=0.368 ; p<.001)$ present a positive association with the dependent variable. Nevertheless, and unlike females, educational level $(\beta=0.090 ; p<.001)$, misbehaviors observed in other road users $(\beta=0.070 ; p<.01)$ and risk perception $(\beta=-0.066 ; p<.001)$ are also significant, while road distractions have a non-significant path to deliberate risky behaviors.

In regard to the positive association between educational level and traffic violations of male pedestrians (see Table 4), an statistical explanation for this link was found, based on the negative correlation between age and education $(r=.260 ; p<.001)$. In other words, participants with higher educational levels were considerably located in lower age segments across all the sample (for which the effect was adjusted), being these subjects those who, simultaneously, tend to report higher traffic violation rates, as graphically shown in Fig. 2.

\subsubsection{Model B: effect of gender on undeliberate risky walking behaviors (errors)}

A second SEM (Model B), built to explain undeliberate risky road behaviors, was also fitted for both genders, keeping a carriable structure identical to model A, but reporting different goodness-of-fit indexes $\left(x^{2}(18)=70.444, p<.001 ; \mathrm{CMIN} / \mathrm{df}=3.914 ; \mathrm{NFI}=.941 ; \mathrm{CFI}=.954\right.$;
$\mathrm{TLI}=.921 ; \mathrm{IFI}=.955 ; \mathrm{RMSEA}=.052, \mathrm{IC} 90 \%[.040-.065])$, that were indicative of an adequate model fit as well.

Model B is presented in the form of two merged graphic models (for both female and male pedestrians) in Fig. 2. According to the model's standardized path coefficients (see Table 5 and values next to solid lines in Fig. 2), this second MGSEM showed that, in the case of female pedestrians, unintended risky behaviors (i.e., errors) are significantly and positively explained by road distractions $(\beta=0.273 ; p<.001)$, their level of interaction with ICTs ( $\beta=0.147 ; p<.001)$, and the sensationseeking trait $(\beta=0.380 ; p<.001)$. On the other hand, model A (for traffic violations), which includes age as a significant explaining variable, does not explain walking-error rates among neither males nor females. In the case of errors, female pedestrians' age. The same happens for both educational level and road misbehaviors observed in other road users.

For what specifically' concerns male pedestrians, positive associations were found between road distractions $(\beta=0.228 ; p<.001)$, interaction with ICTs $(\beta=0.107 ; p<.001)$, sensation seeking trait $(\beta=0.381 ; p<.001)$ and the rate of performed undeliberate risky behaviors. Moreover, and differently from the case of females, risk perception $(\beta=-0.115 ; p<.001)$ yet has a significant role in male pedestrians' walking errors (Fig. 3).

\section{Discussion and conclusion}

Based on the data provided by 1070 Spanish pedestrians who took part this research, and bearing in mind the core study aim, this paper examined the relationships between demographic/psychosocial factors and the self-reported involvement in risky or "aberrant" road behaviors (either errors or violations) in both genders. Through the multi-group structural equation modeling (MGSEM) approach, we found empirical evidence supporting the hypothesis that there are key gender-related differences in the explanation of pedestrians' road behaviors, i.e., finding how these factors may differentially influence their self-reported risky behaviors performed while walking across genders.

Previous empirical evidences retrieved from different groups of both motorized and non-motorized road users have systematically shown how "key" sociodemographic factors, such as gender (Cordelleri et al., 
Table 3

Results of the measurement model.

\begin{tabular}{|c|c|c|c|c|c|c|c|}
\hline \multirow[t]{2}{*}{ Variable } & \multirow[t]{2}{*}{ Component } & \multicolumn{2}{|c|}{ Descriptive statistics } & \multicolumn{2}{|c|}{ Standardized factor loadings ${ }^{3}$} & \multicolumn{2}{|c|}{ Reliability measures } \\
\hline & & $M^{1}$ & $\mathrm{SD}^{2}$ & $\lambda$ Coefficients $^{4}$ & $\mathrm{SE}^{5}$ & $\mathrm{CRI}^{6}$ & Cronbach's Alpha \\
\hline \multirow{4}{*}{ Observed misbehaviors } & OM1 & 2.25 & .85 & .818 & .033 & \multirow{4}{*}{.986} & \multirow{4}{*}{.890} \\
\hline & OM2 & 2.19 & .81 & .817 & .033 & & \\
\hline & OM3 & 1.98 & .78 & .848 & .034 & & \\
\hline & OM4 & 1.94 & .76 & .745 & .037 & & \\
\hline \multirow{8}{*}{ Road distractions } & RDI1 & .80 & .40 & .344 & .053 & \multirow{8}{*}{.890} & \multirow{8}{*}{.652} \\
\hline & RDI2 & .61 & .49 & .358 & .182 & & \\
\hline & RDI3 & .27 & .45 & .471 & .193 & & \\
\hline & RDI4 & .46 & .49 & .320 & .162 & & \\
\hline & RDI5 & .76 & .42 & .310 & .139 & & \\
\hline & RDI6 & .53 & .49 & .434 & .206 & & \\
\hline & RDI7 & .67 & .47 & .574 & .233 & & \\
\hline & RDI8 & .66 & .47 & .645 & .258 & & \\
\hline \multirow{8}{*}{ Sensation seeking } & BSSS1 & 1.38 & 1.23 & .531 & .038 & \multirow{8}{*}{.988} & \multirow{8}{*}{.875} \\
\hline & BSSS2 & .95 & .815 & .597 & .036 & & \\
\hline & BSSS3 & 1.01 & .99 & .688 & .039 & & \\
\hline & BSSS4 & 1.13 & 1.09 & .705 & .041 & & \\
\hline & BSSS5 & 1.05 & 1.03 & .778 & .041 & & \\
\hline & BSSS6 & .93 & .91 & .730 & .039 & & \\
\hline & BSSS7 & 1.10 & .98 & .710 & .044 & & \\
\hline & BSSS8 & .96 & .95 & .741 & .085 & & \\
\hline \multirow{7}{*}{ Risk Perception } & RPRS1 & 3.23 & .95 & .714 & .037 & \multirow{7}{*}{.984} & \multirow{7}{*}{.851} \\
\hline & RPRS2 & 2.03 & 1.22 & .454 & .059 & & \\
\hline & RPRS3 & 3.06 & 1.01 & .777 & .049 & & \\
\hline & RPRS4 & 2.73 & 1.04 & .684 & .051 & & \\
\hline & RPRS5 & 3.07 & 1.21 & .608 & .059 & & \\
\hline & RPRS6 & 3.07 & 1.05 & .780 & .052 & & \\
\hline & RPRS7 & 2.87 & 1.08 & .751 & .053 & & \\
\hline \multirow{15}{*}{ Traffic violations } & WBQ1 & 1.99 & .96 & .573 & .048 & & \\
\hline & WBQ2 & 1.88 & 1.01 & .608 & .052 & & \\
\hline & WBQ3 & 1.20 & .95 & .461 & .046 & & \\
\hline & WBQ4 & 1.37 & 1.07 & .558 & .053 & & \\
\hline & WBQ5 & 1.85 & 1.16 & .703 & .062 & & \\
\hline & WBQ6 & 1.94 & 1.21 & .578 & .051 & & \\
\hline & WBQ7 & 1.09 & 1.02 & .463 & .050 & & \\
\hline & WBQ8 & .68 & .93 & .485 & .046 & & \\
\hline & WBQ9 & 1.93 & 1.27 & .623 & .065 & .989 & .888 \\
\hline & WBQ10 & 1.09 & 1.17 & .548 & .059 & & \\
\hline & WBQ11 & 1.76 & 1.48 & .549 & .075 & & \\
\hline & WBQ12 & 1.59 & 1.20 & .541 & .060 & & \\
\hline & WBQ13 & 1.96 & 1.19 & .613 & .061 & & \\
\hline & WBQ14 & 2.15 & 1.04 & .495 & .052 & & \\
\hline & WBQ15 & 1.06 & .99 & .540 & .042 & & \\
\hline & WBQ16 & 1.74 & 1.18 & .617 & .060 & & \\
\hline & WBQ17 & .46 & .69 & .761 & .060 & & \\
\hline & WBQ18 & .54 & .72 & .672 & .058 & & \\
\hline & WBQ19 & .48 & .68 & .670 & .054 & & \\
\hline & WBQ20 & .57 & .79 & .475 & .059 & & \\
\hline Frrors & WBQ21 & 1.18 & .84 & .600 & .068 & & \\
\hline Errors & WBQ22 & .73 & .79 & .654 & .065 & .984 & .870 \\
\hline & WBQ23 & .77 & .88 & .639 & .067 & & \\
\hline & WBQ24 & .79 & .87 & .613 & .068 & & \\
\hline & WBQ25 & 1.10 & .87 & .655 & .071 & & \\
\hline & WBQ26 & .64 & .81 & .592 & .050 & & \\
\hline
\end{tabular}

Notes: ${ }^{1} \mathrm{M}=$ Arithmetic mean; ${ }^{2} \mathrm{SD}=$ Standard Deviation; ${ }^{3}$ All $p<0.001 ;{ }^{4}$ Factor loading; ${ }^{5} \mathrm{SE}=$ Standard Error; ${ }^{6} \mathrm{CRI}=\mathrm{Composite}$ Reliability Index.

2016; Onieva-García et al., 2016; Barr et al., 2015), age (Ferenchack, 2016; Holland and Hill, 2007; Yagil, 1998) and education (Sami et al., 2013; Lourens et al., 1999), may contribute to differentially predict traffic crashes suffered by them. Moreover, even though risky behaviors do not necessarily result in traffic causalities, it is well-known that the latter are, indeed, largely influenced by the first (Ojo et al., 2019; Useche et al., 2018a; Ngueutsa and Kouabenan, 2017; Thomas et al., 2013). Thus, it seems to be pertinent to use integrated analysis methods to depict the structural differences potentially existing (in this case) between genders, that may affect the safety outcomes of both pedestrians and other types of road user. For instance, a previous study addressing this same research question among bicyclists, that used a similar -although not identical- set of variables as predictors found that both communalities and key differences characterize the risky road behavior between males and females (Useche et al., 2018b).
In this regard, an extensive amount of comparative researches support the idea that, although several similarities still exist between males and females, there are key differences in terms of many factors potentially influencing our daily life behaviors and outcomes. Good examples of it are the case of personality - even if approached from different theoretical models (Cross et al., 2013), risk perception (Cordellieri et al., 2016; Dejoy, 1992), sources of road distraction and their impact (Swedler et al., 2012) and the extent to which pedestrians interact with new technologies - such as smartphones and other connected devices (Chen et al., 2017). For the case of our study, these findings will be summarized along the next heading. 


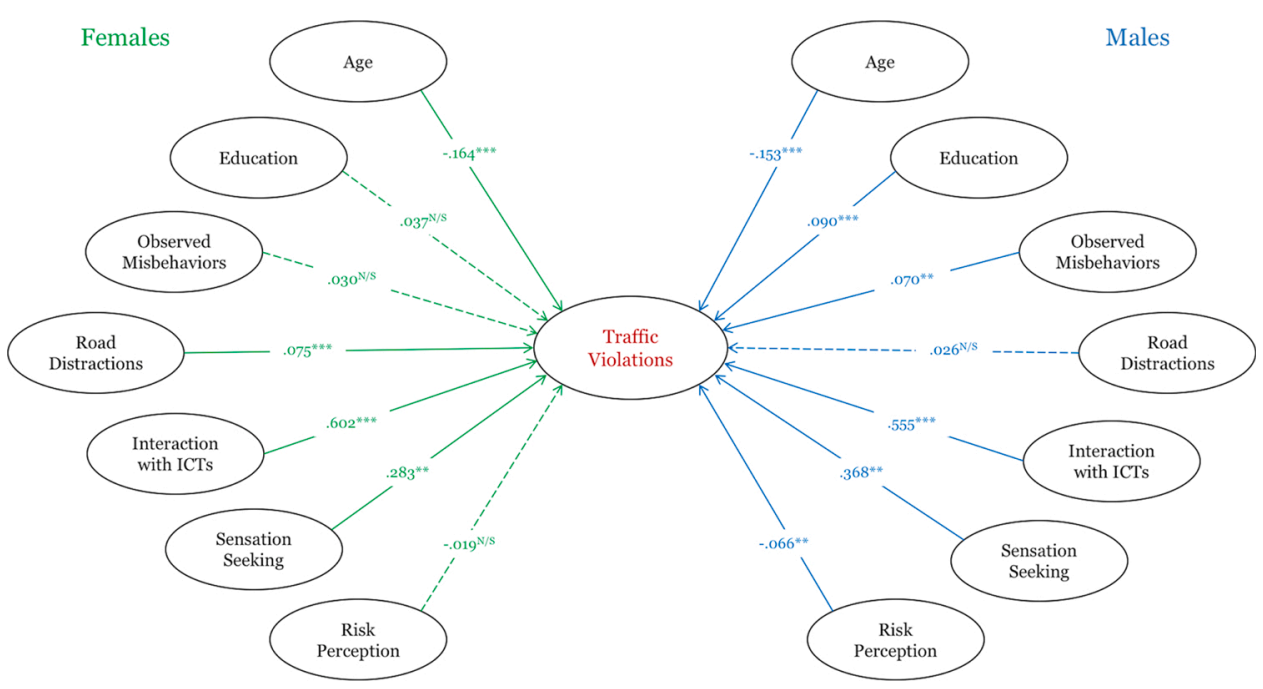

Fig. 1. Two-group structural model showing standardized path coefficients for pedestrian traffic violations: women (left) and men (right). ${ }^{\mathrm{N} / \mathrm{s}}$ Non-significant path (discontinuous arrows); ${ }^{* *} p<0.01 ;{ }^{* *} p<0.001$. Additional data on the model's paths and coefficients are presented in Table 4 .

Table 4

Multi-group SEM Model to predict deliberate Risky Behaviors (Traffic Violations).

\begin{tabular}{|c|c|c|c|c|c|c|}
\hline \multicolumn{7}{|c|}{ Group 1: Females } \\
\hline Path & & & SPC & S.E. & C.R. & $\mathrm{P}$ \\
\hline $\begin{array}{l}\text { Traffic } \\
\text { Violations }\end{array}$ & $\leftarrow$ & Age & -.153 & .001 & -6.256 & $* * *$ \\
\hline $\begin{array}{l}\text { Traffic } \\
\text { Violations }\end{array}$ & $\longleftarrow$ & Education & .037 & .013 & 1.771 & .077 \\
\hline $\begin{array}{l}\text { Traffic } \\
\text { Violations }\end{array}$ & $\leftarrow$ & $\begin{array}{l}\text { Observed } \\
\text { Misbehaviors }\end{array}$ & .030 & .017 & 1.501 & .133 \\
\hline $\begin{array}{l}\text { Traffic } \\
\text { Violations }\end{array}$ & $\leftarrow$ & Road Distractions & .075 & .007 & 3.872 & $* * *$ \\
\hline $\begin{array}{l}\text { Traffic } \\
\text { Violations }\end{array}$ & $\longleftarrow$ & Sensation Seeking & .283 & .015 & 13.135 & $* * *$ \\
\hline $\begin{array}{l}\text { Traffic } \\
\text { Violations }\end{array}$ & $\leftarrow$ & $\begin{array}{l}\text { Interaction with } \\
\text { ICTs }\end{array}$ & .602 & .017 & 23.899 & $* * *$ \\
\hline $\begin{array}{l}\text { Traffic } \\
\text { Violations }\end{array}$ & $\longleftarrow$ & Risk Perception & -.019 & .016 & -.945 & .345 \\
\hline \multicolumn{7}{|c|}{ Group 2: Males } \\
\hline Path & & & SPC & S.E. & C.R. & $\mathrm{P}$ \\
\hline $\begin{array}{l}\text { Traffic } \\
\text { Violations }\end{array}$ & $\leftarrow$ & Age & -.164 & .001 & -5.834 & $* * *$ \\
\hline $\begin{array}{l}\text { Traffic } \\
\text { Violations }\end{array}$ & $\longleftarrow$ & Education & .090 & .015 & 3.580 & $* * *$ \\
\hline $\begin{array}{l}\text { Traffic } \\
\text { Violations }\end{array}$ & $\leftarrow$ & $\begin{array}{l}\text { Observed } \\
\text { Misbehaviors }\end{array}$ & .070 & .022 & 2.737 & $* *$ \\
\hline $\begin{array}{l}\text { Traffic } \\
\text { Violations }\end{array}$ & $\leftarrow$ & Road Distractions & .026 & .008 & 1.047 & .295 \\
\hline $\begin{array}{l}\text { Traffic } \\
\text { Violations }\end{array}$ & $\leftarrow$ & Sensation Seeking & .368 & .017 & 13.996 & $* * *$ \\
\hline $\begin{array}{l}\text { Traffic } \\
\text { Violations }\end{array}$ & $\longleftarrow$ & $\begin{array}{l}\text { Interaction with } \\
\text { ICTs }\end{array}$ & .555 & .020 & 19.337 & $* * *$ \\
\hline $\begin{array}{l}\text { Traffic } \\
\text { Violations }\end{array}$ & $\longleftarrow$ & Risk Perception & -.066 & .019 & -2.598 & $* *$ \\
\hline
\end{tabular}

\subsection{Summary: Gender-based structural differences and similarities in} risky walking behaviors

The core analysis factor addressed in this study, as a split category, was gender. In this regard, our research aimed to study the structural differences (and similarities) between male and female pedestrians in many factors, theoretically influencing their risky walking behaviors. The two multi-group SEM models allowed us to determine that specifically for each independent variable:

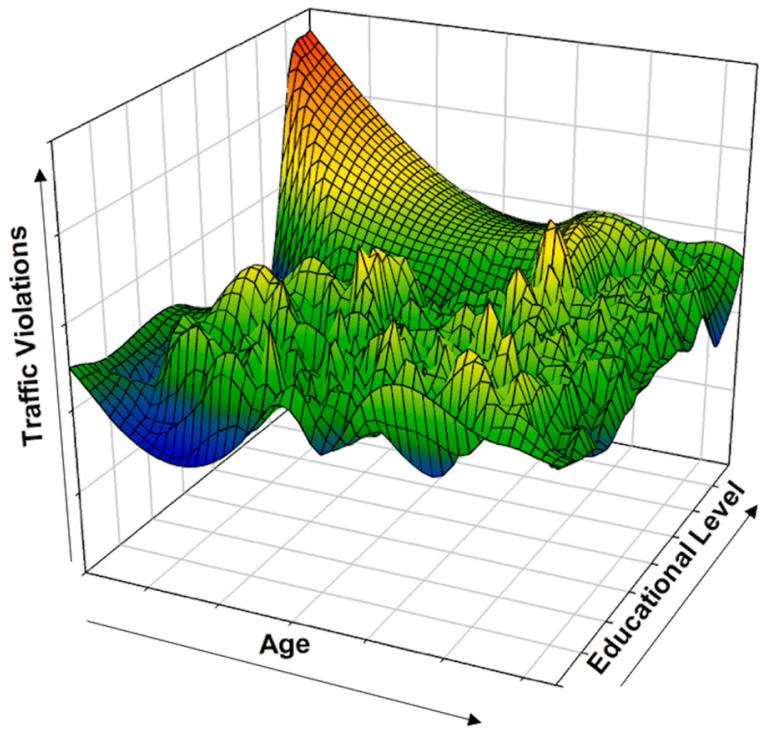

Fig. 2. Graphical associations among pedestrians' age, educational level and traffic violation rates.

\subsubsection{Age and educational level}

The first variable significantly explained deliberate risky behaviors in the case of both male and female pedestrians (i.e., the younger the individual, the higher the frequency of committed traffic violations). On the other hand, in the case of neither males nor females, age values had significant effects on undeliberate misbehaviors or errors. In other words, no gender differences were found in the case of age, which appeared to have a similar influence in both cases.

Unlike the case of age, participant's education explains differences in traffic violations while walking; even though the effect is not significant in females, a positive association was found in the case of male pedestrians. As for the case of undeliberate misbehaviors, the educational level did not have a significant effect on any of the two genders. However, it is worth remembering that the mean age of the participants of this study was around 30 years of age, and about half of them had university studies. Therefore, we had an overall profile of "young adult pedestrian with mid or high educational level", values that -apart from being correlated- denote a potential gap related to the sample, reason why this issue may limit the generalizability of the results in regard to 
Table 5

Multi-group SEM Model to predict undeliberate Risky Behaviors (Errors).

\begin{tabular}{|c|c|c|c|c|c|c|}
\hline \multicolumn{7}{|c|}{ Group 1: Females } \\
\hline Path & & & SPC & S.E. & C.R. & $\mathrm{P}$ \\
\hline Errors & $\longleftarrow$ & Age & -.038 & .002 & -1.014 & .311 \\
\hline Errors & $\longleftarrow$ & Education & -.065 & .017 & -1.857 & .063 \\
\hline Errors & $\longleftarrow$ & Observed Misbehaviors & .032 & .016 & .971 & .332 \\
\hline Errors & $\longleftarrow$ & Road Distractions & .273 & .009 & 8.274 & $* * *$ \\
\hline Errors & $\leftarrow$ & Sensation Seeking & .380 & .020 & 10.518 & $* * *$ \\
\hline Errors & $\longleftarrow$ & Interaction with ICTs & .147 & .002 & 3.916 & $* * *$ \\
\hline Errors & $\longleftarrow$ & Risk Perception & -.051 & .015 & -1.533 & .125 \\
\hline \multicolumn{7}{|c|}{ Group 2: Males } \\
\hline Path & & & SPC & S.E. & C.R. & $\mathrm{P}$ \\
\hline Errors & $\longleftarrow$ & Age & -.028 & .002 & -.639 & .523 \\
\hline Errors & $\longleftarrow$ & Education & .026 & .021 & .608 & .543 \\
\hline Errors & $\longleftarrow$ & Observed Misbehaviors & .038 & .022 & .886 & .375 \\
\hline Errors & $\longleftarrow$ & Road Distractions & .228 & .011 & 5.447 & $* * *$ \\
\hline Errors & $\longleftarrow$ & Sensation Seeking & .381 & .024 & 8.667 & $* * *$ \\
\hline Errors & $\longleftarrow$ & Interaction with ICTs & .107 & .023 & 2.456 & $* * *$ \\
\hline Errors & $\longleftarrow$ & Risk Perception & -.115 & .019 & -2.750 & $* *$ \\
\hline
\end{tabular}

different other profiles, such as older pedestrians, as it will be discussed in the limitations of the study as well.

\subsubsection{Road misbehaviors observed in other users}

One of the most interesting findings of this set of structural comparisons is that unlike females (in the case of which it does not influence their deliberate misbehaviors), traffic violations of males can be positively predicted through the degree to which they observe aberrant road behaviors performed by other users of the road. On the other hand, undeliberate misbehaviors of both males and females were not significantly influenced by this variable. In a similar way, but dealing with actively safe (not risky) behaviors, a recent study performed in Spain found that the extent to which both male and female teenagers observe safer road behaviors among their relatives has a significant effect on their positive attitudes towards road safety (Useche et al., 2019), as also discussed by Svenson et al. (1985) in regard to the social learning of passive safety habits among adults in the U.S., and by Shope (2006) as for environmental influences on driving behavior. In other words, and added to the figures provided by the current study, these outcomes may support the assumption by which observing other user's road misbehaviors seems a potential factor encouraging pedestrians to behave in similar ways (Hashemiparast et al., 2017).

\subsubsection{Road distractions}

Road distractions has shown to have a significant effect on the rate of traffic violations commited by female pedestrians, but not on the case of males. In other words, traffic violations performed by women could be influenced by external distractions, while it does not seem to influence the deliberate road misbehaviors of male pedestrians significantly. Although the impact of road distractions on risky walking behaviors have been less studied than the case of motor-vehicle drivers, and researches dealing with pedestrians have been predominantly focused on certain types of distractions (e.g., mobile technologies) on walking performance, there are some good insights available in the existing literature. For instance, and even though distracted walking has been widely associated to unintentional risky behaviors (errors) of pedestrians (Jiang et al., 2018; Schwebel et al., 2012), previous studies such as the performed by Thompson et al. (2013) have found that pedestrians more exposed to distracting sources (e.g., text messaging and overall mobile phone using) do not only commit more errors, but also are up to 3.9 times more likely to performing traffic violations such as disobeying lights or crossing midblock. Furthermore, this previous research has also shown how "distracted female pedestrians" were twice as likely to exhibit at least one unsafe crossing behaviour, relative to male counterparts, coherently with the findings of this study.

The case of errors is -as expected- different (no gender differences were indentified), being these paths very significant and similar in terms of both positive directionality and magnitude (similar beta coefficients), in both genders, i.e., road distractions highly affect undeliberate risky behaviors of male and female individuals.

\subsubsection{Interaction with ICTs}

Much has been said in the literature about the hazards implied by electronic and connected devices used while (e.g.) walking, riding, and driving. Specifically, the assumption by which the progressive involvement of ITCs implies higher behavioral and crash-related risks for different types of road users (including pedestrians) keeps gaining ground in recent literature, especially across researches assessing the safety implications of an increasing on-road interaction with technology (Young et al., 2020; Jiang et al., 2018; Oviedo-Trespalacios et al., 2019; Schwebel et al., 2012). In the case of this study, the results consistently suggest that a greater interaction with ICTs significantly influences the likelihood of commiting both errors and traffic violations - highlighting this issue as a potential thread for walking behavior, regardless of gender.

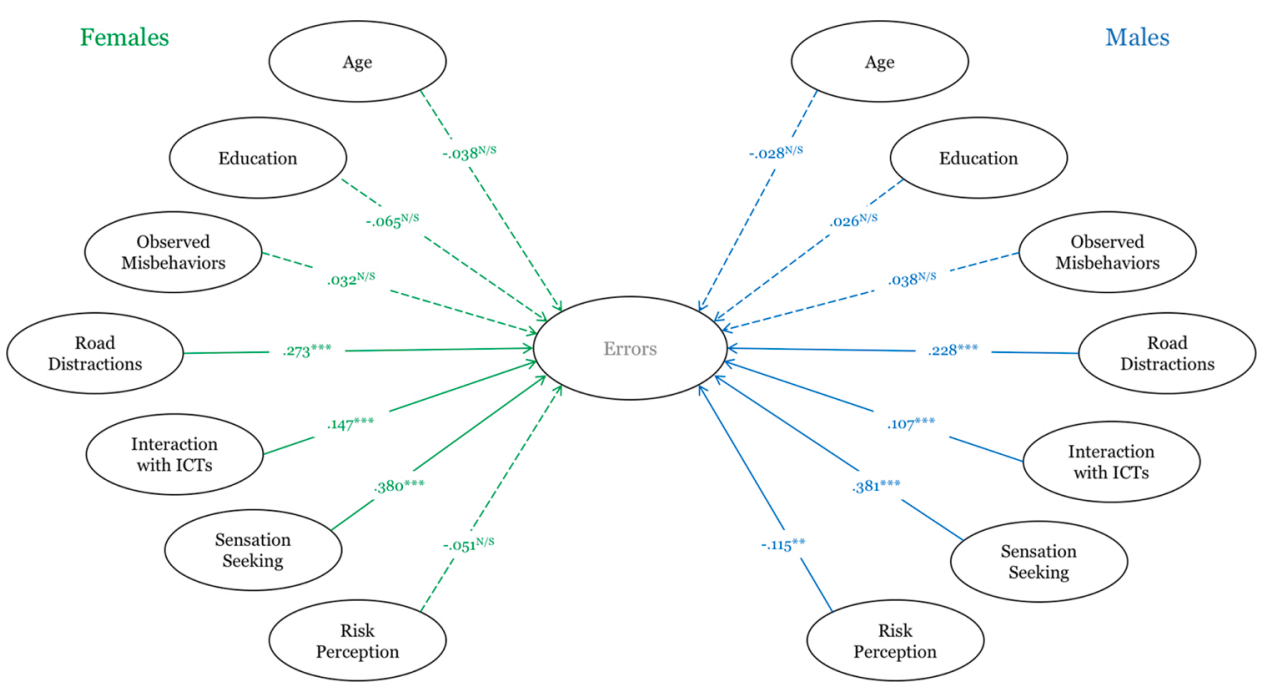

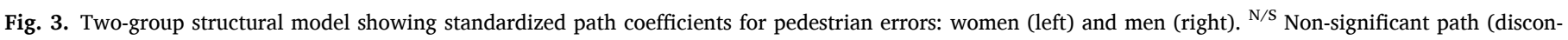
tinuous arrows); ${ }^{* * *} p<0.001$. Additional information is presented in Table 5 . 


\subsubsection{Sensation seeking (personality trait)}

Same as the last variable we addressed, this personality trait has shown to be a significant contributor to both types of aberrant walking behaviors. In other words, higher scores of both genders ("sensation seekers") get involved in errors and violations while walking with a higher frequency. Consistently, previous literature exploring both types of risky road behavior has shown how sensation seeking is not only associated to both road errors and violations, but in the case of pedestrians may ( $i$ ) enhance the likelihood of getting involved in unexpected/ demanding road situations, and (ii) constitute a reliable predictor of pedestrian's traffic violations, such as breaking crossing rules (Freeman and Rakotonirainy, 2015; Rosenbloom, 2006).

\subsubsection{Risk perception}

Significant for males but non-significant for female pedestrians in both cases, risk perception exerts a negative effect on the traffic violations and errors performed by males. In other words, this key genderbased difference implies that male "walkers" with a lower road risk perception perform both deliberate and undeliberate aberrant road behaviors significantly more frequently than those reporting higher levels. Similar outcomes in regard to the gender-based differential contribution of risk perception to risky behaviors have been found in studies dealing with other type of non-motorized road users (i.e., cyclists), where greater degrees of road risk perception were associated to less likelihood to perform risky road behaviors among males, but not among females (Useche et al., 2018a). Although the literature in this regard (to explain why) is still scarce, other studies on road risk-taking have found that females may have more discordance between ther declared and the actually observed walking behavior than male pedestrians (Papadimitriou et al., 2016). Another plausible explanation could be that, as highlighted in recent studies, even if risk perception between a male and female subject were similar, the last differs in their level of concern about such risks -usually higher than in males-, allowing to hypothesize that, in addition to risk perception, it might contribute to inhibit risky road behaviors (Cordelleri et al., 2016).

\section{Limitations of the study and further research}

Although this study used a sample that was representative of the Spanish population, and the essential statistical parameters, Goodnessof-Fit indexes, and theoretical assumptions were coherently achieved during the data analysis, there is a set of limitations and potential biasing sources that must be acknowledged. The questionnaire was completely anonymous, and the non-existence of right or wrong answers was emphasized; however, this does not inhibit the influence of common method biases (CMBs) and common method variance (CMV), mainly if sensitive topics related to social and personal safety-related behavior are addressed (Af Wåhlberg and Dorn, 2015). Also, it is worth empahizing that, although it makes sampling procedures easier and convenient for researchers, convenience sampling involves representativeness biases, especially in online-based recruitment processes, such as mailing lists and social network using. For instance, the study can underrepresent certain segments of the population less likely to be present in significant numbers in the on-line environment (e.g., older adults, people at low interaction with information technologies), making generalizing the data to the general public potentially problematic when the outcomes are not interpreted in consideration of these potential shortcomings (Kelfve et al., 2013; McInroy, 2016). Moreover, and as it happens in most of the cross-sectional studies on this issue, we measured and included in the models a pertinent -but still short- set of variables, but other factors could even influence walking road behaviors. Also, it is suggestible to acquire more insights on this interesting issue through in-depth interviews and mixed research methods, to maximize the explanation of gender-based differences in this vulnerable group of road users.

\section{CRediT authorship contribution statement}

Sergio A. Useche: Conceptualization, Methodology, Investigation, Writing - original draft, Writing - review \& editing. Amin Mohamadi Hezaveh: Investigation, Data curation, Writing - original draft. Francisco J. Llamazares: Resources, Supervision, Writing - review \& editing. Christopher Cherry: Visualization, Supervision, Writing - review \& editing.

\section{Declaration of Competing Interest}

The authors report no declarations of interest.

\section{Acknowledgments}

The authors would like to thank the participants, research assistants, and institutional stakeholders for supporting this study. Specifically, thanks to Dr. Luis Montoro González for the support in the data collectionto Ariel Ortiz for the technical advising provided and to Boris Cendales for the reading proof of the final version of the manuscript.

\section{References}

Af Wåhlberg, A.E., Dorn, L., 2015. How reliable are self-report measures of mileage, violations and crashes? Saf. Sci. 76, 67-73. https://doi.org/10.1016/j. ssci.2015.02.020.

Anderson, E., Shivakumar, G., 2013. Effects of exercise and physical activity on anxiety. Front. Psychiatry 4, 27. https://doi.org/10.3389/fpsyt.2013.00027.

Assailly, J.P., 1993. Accidents of pedestrian children, their prevention and the education of the pedestrian child]. Institut National De Recherche Sur Les Transportes Et Leur Sécurité. Technical Report No. 163. INRETS, Paris.

Audrey, S., Procter, S., Cooper, A.R., 2014. The contribution of walking to work to adult physical activity levels: a cross sectional study. Int. J. Behav. Nutr. Phys. Act. 11 (1), 37. https://doi.org/10.1186/1479-5868-11-37.

Barić, D., Pilko, H., Starčević, M., 2018. Introducing experiment in pedestrian behaviour and risk perception study at urban level crossing. Int. J. Inj. Contr. Saf. Promot. 25 (1), 102-112. https://doi.org/10.1080/17457300.2017.1341934.

Barr, G.C.Jr., Kane, K.E., Barraco, R.D., Rayburg, T., Demers, L., Kraus, C.K., Greenberg, M.R., Rupp, V.A., Hamilton, K.M., Kane, B.G., 2015. Gender differences in perceptions and self-reported driving behaviors among teenagers. J. Emerg. Med. 48 (3), 366-370. https://doi.org/10.1016/j.jemermed.2014.09.055 e3.

Barr, A., Simons, K., Mavoa, S., Badland, H., Giles-Corti, B., Scheurer, J., Korevaar, E., Stewart, J., Bentley, R., 2019. Daily walking among commuters: a cross-sectional study of associations with residential, work, and regional accessibility in Melbourne, Australia (2012-2014). Environ. Health Perspect. 127 (9), 97004. https://doi.org/ 10.1289/EHP3395.

Barranco-Ruiz, Y., Cruz León, C., Villa-González, E., Palma Leal, X., Chillón, P., Rodríguez-Rodríguez, F., 2019. Active commuting to university and its association with sociodemographic factors and physical activity levels in chilean students. Medicina (Kaunas) 55 (5), 152. https://doi.org/10.3390/medicina55050152.

Beauducel, A., Herzberg, P.Y., 2006. On the performance of maximum likelihood versus means and variance adjusted weighted least squares estimation in CFA. Struct. Equ. Model. A Multidiscip. J. 13 (2), 186-203. https://doi.org/10.1207/ s15328007sem1302_2.

Chen, H.Y., Donmez, B., 2016. What drives technology-based distractions? A structural equation model on social-psychological factors of technology-based driver distraction engagement. Accid. Anal. Prev. 91, 166-174. https://doi.org/10.1016/j. aap.2015.08.015.

Chen, B., Liu, F., Ding, S., Ying, X., Wang, L., Wen, Y., 2017. Gender differences in factors associated with smartphone addiction: a cross-sectional study among medical college students. BMC Psychiatry 17 (1), 341. https://doi.org/10.1186/s12888-0171503-z.

Colberg, S.R., Sigal, R.J., Fernhall, B., Regensteiner, J.G., Blissmer, B.J., Rubin, R.R., Chasan-Taber, L., Albright, A.L., Braun, B., American College of Sports Medicine, American Diabetes Association, 2010. Exercise and type 2 diabetes: the American College of Sports Medicine and the American Diabetes Association: joint position statement. Diabetes Care 33 (12), e147-e167. https://doi.org/10.2337/dc10-9990.

Cordellieri, P., Baralla, F., Ferlazzo, F., Sgalla, R., Piccardi, L., Giannini, A.M., 2016. Gender effects in young road users on road safety attitudes, behaviors and risk perception. Front. Psychol. 7, 1412. https://doi.org/10.3389/fpsyg.2016.01412.

Cross, C.P., Cyrenne, D.L., Brown, G.R., 2013. Sex differences in sensation-seeking: a meta-analysis. Sci. Rep. 3, 2486. https://doi.org/10.1038/srep02486.

Deb, S., Strawderman, L., DuBien, J., Smith, B., Carruth, D.W., Garrison, T.M., 2017. Evaluating pedestrian behavior at crosswalks: validation of a pedestrian behavior questionnaire for the U.S. Population. Accid. Anal. Prev. 106, 191-201. https://doi. org/10.1016/j.aap.2017.05.02.

Dejoy, D.M., 1992. An examination of gender differences in traffic accident risk perception. Accid. Anal. Prev. 24 (3), 237-246. https://doi.org/10.1016/0001-4575 (92)90003-2. 
Elliott, M.A., Baughan, C.J., Sexton, B.F., 2007. Errors and violations in relation to motorcyclists' crash risk. Accid. Anal. Prev. 39 (3), 491-499. https://doi.org/ 10.1016/j.aap.2006.08.012.

Ferenchack, N.N., 2016. Pedestrian age and gender in relation to crossing behavior at midblock crossings in India. J. Traffic Transp. Eng. 3 (4), 345-351. https://doi.org/ 10.1016/j.jtte.2015.12.001.

Finney, S.J., DiStefano, C., 2013. Nonnormal and categorical data in structural equation modeling. In: Hancock, G.R., Mueller, R.O. (Eds.), Quantitative Methods in Education and the Behavioral Sciences: Issues, Research, and Teaching. Structural Equation Modeling: A Second Course. IAP Information Age Publishing, pp. 439-492.

Freeman, J., Rakotonirainy, A., 2015. Mistakes or deliberate violations? A study into the origins of rule breaking at pedestrian train crossings. Accid. Anal. Prev. 77, 45-50. https://doi.org/10.1016/j.aap.2015.01.015.

Hanson, S., Jones, A., 2015. Is there evidence that walking groups have health benefits? A systematic review and meta-analysis. Br. J. Sports Med. 49 (11), 710-715. https:// doi.org/10.1136/bjsports-2014-094157.

Hashemiparast, M., Negarandeh, R., Montazeri, A., 2017. How young pedestrians do explain their risky road crossing behaviors? A qualitative study in Iran. Health Promot. Perspect. 7 (3), 140-144. https://doi.org/10.15171/hpp.2017.26.

Hezaveh, A.M., Cherry, C.F., 2018. Walking under the influence of the alcohol: a case study of pedestrian crashes in Tennessee. Accid. Anal. Prev. 121, 64-70. https://doi. org/10.1016/j.aap.2018.09.002.

Hezaveh, A.M., Mohdej, A., Cherry, C.F., 2018a. Pedestrian crashes in Tennessee: a data mining approach. Presented at the Transportation Research Board 97th Annual Meeting (Washington DC, USA) from 2018-1-7 to 2018-1-11.

Hezaveh, A.M., Zavareh, M.F., Cherry, C.F., Nordfjærn, T., 2018b. Errors and violations in relation to bicyclists' crash risks: development of the Bicycle Rider Behavior Questionnaire (BRBQ). J. Transp. Health 8, 289-298. https://doi.org/10.1016/j. jth.2017.11.003.

Hökerberg, Y.H., Reichenheim, M.E., Faerstein, E., Passos, S.R., Fritzell, J., Toivanen, S., Westerlund, H., 2014. Cross-cultural validity of the demand-control questionnaire: Swedish and Brazilian workers. Rev. Saude Publica 48 (3), 486-496. https://doi. org/10.1590/s0034-8910.2014048005126.

Holland, C.A., Hill, R., 2007. The effects of age, gender and driver status on pedestrians' intentions to cross the road in risky situations. Accid. Anal. Prev. 39, 224-237. https://doi.org/10.1016/j.aap.2006.07.003.

Hu, L.T., Bentler, P.M., 1999. Cutoff criteria for fit indexes in covariance structure analysis: conventional criteria versus new alternatives. Struct. Equ. Model. 6 (1), 1-55. https://doi.org/10.1080/10705519909540118.

Jiang, K., Ling, F., Feng, Z., Ma, C., Kumfer, W., Shao, C., Wang, K., 2018. Effects of mobile phone distraction on pedestrians' crossing behavior and visual attention allocation at a signalized intersection: an outdoor experimental study. Accid. Anal. Prev. 115, 170-177. https://doi.org/10.1016/j.aap.2018.03.019.

Kelfve, S., Thorslund, M., Lennartsson, C., 2013. Sampling and non-response bias on health-outcomes in surveys of the oldest old. Eur. J. Ageing 10 (3), 237-245. https:// doi.org/10.1007/s10433-013-0275-7.

Khan, M., Grivna, M., Nauman, J., Soteriades, E.S., Cevik, A.A., Hashim, M.J., Govender, R., Al Azeezi, S.R., 2020. Global incidence and mortality patterns of pedestrian road traffic injuries by sociodemographic index, with forecasting: findings from the global burden of diseases, injuries, and risk factors 2017 study. Int. J. Environ. Res. Public Health 17 (6), 2135. https://doi.org/10.3390/ ijerph17062135.

Kline, R.B., 2011. Principles and Practice of Structural Equation Modeling. The Guilford Press, New York, pp. 204-214.

Lourens, P.F., Vissers, J.A., Jessurun, M., 1999. Annual mileage, driving violations, and accident involvement in relation to drivers' sex, age, and level of education. Accid. Anal. Prev. 31 (5), 593-597. https://doi.org/10.1016/s0001-4575(99)00015-9.

Marselle, M.R., Irvine, K.N., Warber, S.L., 2013. Walking for well-being: are group walks in certain types of natural environments better for well-being than group walks in urban environments? Int. J. Environ. Res. Public Health 10 (11), 5603-5628. https://doi.org/10.3390/ijerph10115603.

Marsh, H.W., Hau, K.T., Wen, Z., 2004. In search of golden rules: comment on hypothesis-testing approaches to setting cutoff values for fit indexes and dangers in overgeneralizing Hu and Bentler's (1999) findings. Struct. Equ. Model. 11, 320-341. https://doi.org/10.1207/s15328007sem110322.

McInroy, L.B., 2016. Pitfalls, potentials, and ethics of online survey research: LGBTQ and other marginalized and hard-to-Access youths. Soc. Work Res. 40 (2), 83-94. https://doi.org/10.1093/swr/svw005.

Miles, J., Shevlin, M., 2007. A time and a place for incremental fit indices. Pers. Individ. Dif. 42 (5), 869-874. https://doi.org/10.1016/j.paid.2006.09.022.

Miller, C.H., Quick, B.L., 2010. Sensation seeking and psychological reactance as health risk predictors for an emerging adult population. Health Commun. 25 (3), 266-275. https://doi.org/10.1080/10410231003698945.

Montoro, L., Useche, S.A., Alonso, F., Lijarcio, I., Bosó-Seguí, P., Martí-Belda, A., 2019. Perceived safety and attributed value as predictors of the intention to use autonomous vehicles: a national study with Spanish drivers. Saf. Sci. 120, 865-876. https://doi.org/10.1016/j.ssci.2019.07.041.

Morera, O.F., Stokes, S.M., 2016. Coefficient $\alpha$ as a measure of test score reliability: review of 3 popular misconceptions. Am. J. Public Health 106 (3), 458-461. https:// doi.org/10.2105/AJPH.2015.302993.

Ngueutsa, R., Kouabenan, D.R., 2017. Accident history, risk perception and traffic safe behaviour. Ergonomics 60 (9), 1273-1282. https://doi.org/10.1080/ 00140139.2016 .1259508

Oja, P., Vuori, I., Paronen, O., 1998. Daily walking and cycling to work: their utility as health-enhancing physical activity. Patient Educ. Couns. 33 (1 Suppl), S87-S94. https://doi.org/10.1016/s0738-3991(98)00013-5.
Ojo, T., Adetona, C.O., Agyemang, W., Afukaar, F.K., 2019. Pedestrian risky behavior and safety at zebra crossings in a Ghanaian metropolitan area. Traffic Inj. Prev. 20 (2), 216-219. https://doi.org/10.1080/15389588.2018.1555372.

Onieva-García, M.A., Martínez-Ruiz, V., Lardelli-Claret, P., Jiménez-Moleón, J.J., Amezcua-Prieto, C., de Dios Luna-Del-Castillo, J., Jiménez-Mejías, E., 2016. Gender and age differences in components of traffic-related pedestrian death rates: exposure, risk of crash and fatality rate. Inj. Epidemiol. 3 (1), 14. https://doi.org/10.1186/ s40621-016-0079-2.

Oviedo-Trespalacios, O., Nandavar, S., Newton, J., Demant, D., Phillips, J.G., 2019. Problematic use of mobile phones in Australia...Is it getting worse? Front. Psychiatry 10, 105. https://doi.org/10.3389/fpsyt.2019.00105.

Page, N.C., Nilsson, V.O., 2017. Active commuting: workplace health promotion for improved employee well-being and organizational behavior. Front. Psychol. 7, 1994. https://doi.org/10.3389/fpsyg.2016.01994.

Papadimitriou, E., Lassarre, S., Yannis, G., 2016. Pedestrian risk taking while road crossing: a comparison of observed and declared behaviour. Transp. Res. Procedia 14, 4354-4363. https://doi.org/10.1016/j.trpro.2016.05.357.

Politi, P.L., Piccinelli, M., Wilkinson, G., 1994. Reliability, validity and factor structure of the 12-item general health questionnaire among young males in Italy. Acta Psychiatr. Scand. 90 (6), 432-437. https://doi.org/10.1111/j.1600-0447.1994. tb01620.x.

Poó, F.M., Ledesma, R.D., Trujillo, R., 2018. Pedestrian crossing behavior, an observational study in the city of Ushuaia, Argentina. Traffic Inj. Prev. 19 (3), 305-310. https://doi.org/10.1080/15389588.2017.1391380.

Posner, J.C., Liao, E., Winston, F.K., Cnaan, A., Shaw, K.N., Durbin, D.R., 2002. Exposure to traffic among urban children injured as pedestrians. Inj. Prev. 8 (3), 231-235. https://doi.org/10.1136/ip.8.3.231.

Rankavat, S., Tiwari, G., 2016. Pedestrians risk perception of traffic crash and built environment features - Delhi, India. Saf. Sci. 87, 1-7. https://doi.org/10.1016/j. ssci.2016.03.009.

Rankavat, S., Tiwari, G., 2019. Pedestrians crossing behavior in Delhi, India. J. Eastern Asia Soc. Transp. Stud. 13, 831-840. https://doi.org/10.11175/easts.13.831.

Reason, J., Manstead, A., Stradling, S., Baxter, J., Campbell, K., 1990. Errors and violations on the roads: a real distinction? Ergonomics 33 (10-11), 1315-1332. https://doi.org/10.1080/00140139008925335.

Rosenbloom, T., 2006. Sensation seeking and pedestrian crossing compliance. Soc. Behav. Pers. 34 (2), 113-122. https://doi.org/10.2224/sbp.2006.34.2.113.

Rosenbloom, T., Nemrodov, D., Barkana, H., 2004. For heaven's sake follow the rules: pedestrians' behavior in an ultra-orthodox and a non-orthodox city. Transp. Res. Part F Traffic Psychol. Behav. 7 (6), 395-404. https://doi.org/10.1016/j. trf.2004.10.004.

Sami, A., Moafian, G., Najafi, A., Aghabeigi, M.R., Yamini, N., Heydari, S.T., Lankarani, K.B., 2013. Educational level and age as contributing factors to road traffic accidents. Chin. J. Traumatol. 16 (5), 281-285.

Schwebel, D.C., Stavrinos, D., Byington, K.W., Davis, T., O'Neal, E.E., de Jong, D., 2012. Distraction and pedestrian safety: how talking on the phone, texting, and listening to music impact crossing the street. Accid. Anal. Prev. 45 (2), 266-271. https://doi. org/10.1016/j.aap.2011.07.011.

Shope, J.T., 2006. Influences on youthful driving behavior and their potential for guiding interventions to reduce crashes. Inj. Prev. 12 (Suppl 1), i9-i14. https://doi.org/ 10.1136/ip.2006.011874.

Stephenson, M.T., Velez, L.F., Chalela, P., Ramírez, A., Hoyle, R.H., 2007. The reliability and validity of the Brief Sensation seeking Scale (BSSS-8) with young adult Latino workers: implications for tobacco and alcohol disparity research. Addiction 102 (2), 79-91. https://doi.org/10.1111/j.1360-0443.2007.01958.x.

Stevens, J.P., 2002. Applied Multivariate Statistics for the Social Sciences, 4th ed. Erlbaum, Hillsdale, NS.

Svenson, O., Fischhoff, B., MacGregor, D., 1985. Perceived driving safety and seatbelt usage. Accid. Anal. Prev. 17 (2), 119-133. https://doi.org/10.1016/0001-4575(85) 90015-6.

Swedler, D.I., Bowman, S.M., Baker, S.P., 2012. Gender and age differences among teen drivers in fatal crashes. Ann. Adv. Automot. Med. 56, 97-106.

Thomas, P., Morris, A., Talbot, R., Fagerlind, H., 2013. Identifying the causes of road crashes in Europe. Ann. Adv. Automot. Med. 57, 13-22.

Thompson, L.L., Rivara, F.P., Ayyagari, R.C., Ebel, B.E., 2013. Impact of social and technological distraction on pedestrian crossing behaviour: an observational study. Inj. Prev. 19 (4), 232-237. https://doi.org/10.1136/injuryprev-2012-040601.

Tom, A., Granié, M.A., 2011. Gender differences in pedestrian rule compliance and visual search at signalized and unsignalized crossroads. Accid. Anal. Prev. 43 (5), 1794-1801. https://doi.org/10.1016/j.aap.2011.04.012.

Useche, S.A., Alonso, F., Montoro, L., Esteban, C., 2018a. Distraction of cyclists: how does it influence their risky behaviors and traffic crashes? PeerJ 6, e5616. https:// doi.org/10.7717/peerj.5616.

Useche, S.A., Montoro, L., Alonso, F., Tortosa, F., 2018b. Does gender really matter? A structural equation model to explain risky and positive cycling behaviors. Accid. Anal. Prev. 118, 86-95. https://doi.org/10.1016/j.aap.2018.05.022.

Useche, S.A., Alonso, F., Montoro, L., Garrigós, L., 2019. More aware, more protected: a cross- sectional study on road safety skills predicting the use of passive safety elements among Spanish teenagers. BMJ Open 9, 35007. https://doi.org/10.1136/ bmjopen-2019-035007.

Useche, S.A., Alonso, F., Montoro, L., 2020. Validation of the Walking Behavior Questionnaire (WBQ): a tool for measuring risky and safe walking from a behavioral perspective. J. Transp. Health 18, 10089. https://doi.org/10.1016/j. jth.2020.100899. 
Wang, H., Schwebel, D.C., Tan, D., Shi, L., Miao, L., 2018. Gender differences in children's pedestrian behaviors: developmental effects. J. Safety Res. 67, 127-133. https://doi.org/10.1016/j.jsr.2018.09.003.

Warburton, D.E., Nicol, C.W., Bredin, S.S., 2006. Health benefits of physical activity: the evidence. CMAJ 174, 801-809. https://doi.org/10.1503/cmaj.051351.

Yagil, D., 1998. Gender and age-related differences in attitudes toward traffic laws and traffic violations. Transp. Res. Part F Traffic Psychol. Behav. 1, 123-135. https://doi. org/10.1016/S1369-8478(98)00010-2.

Yagil, D., 2000. Beliefs, motives and situational factors related to pedestrians' selfreported behavior at signal-controlled crossings. Transp. Res. Part F Traffic Psychol. Behav. 3 (1), 1-13. https://doi.org/10.1016/S1369-8478(00)00004-8.

Yang, L., Panter, J., Griffin, S.J., Ogilvie, D., 2012. Associations between active commuting and physical activity in working adults: cross-sectional results from the Commuting and Health in Cambridge study. Prev. Med. 55 (5), 453-457. https:// doi.org/10.1016/j.ypmed.2012.08.019.

Young, K.L., Stephens, A.N., O’Hern, S., Koppel, S., 2020. Australian cyclists' engagement in secondary tasks. J. Transp. Health 16, 100793. https://doi.org/ 10.1016/j.jth.2019.100793.
Yu, S., Wu, Y., Mrug, S., Wang, H., Ridley, S., Hu, G., Schwebel, D.C., 2020. Pedestrianvehicle crashes: risk perception and responsibility attribution among children, adolescents and adults. J. Inj. Violence Res. 12 (1), 29-38. https://doi.org/10.5249/ jivr.v12i1.1243.

Zhao, W., Ukawa, S., Kawamura, T., Wakai, K., Ando, M., Tsushita, K., Tamakoshi, A. 2015. Health benefits of daily walking on mortality among younger-elderly men with or without major critical diseases in the new integrated suburban seniority investigation project: a prospective cohort study. J. Epidemiol. 25 (10), 609-616. https://doi.org/10.2188/jea.JE20140190.

Zheng, T., Qu, W., Ge, Y., Sun, X., Zhang, K., 2017. The joint effect of personality traits and perceived stress on pedestrian behavior in a Chinese sample. PLoS One 12 (11), e0188153. https://doi.org/10.1371/journal.pone.0188153.

Zhu, M., Zhao, S., Coben, J.H., Smith, G.S., 2013. Why more male pedestrians die in vehicle-pedestrian collisions than female pedestrians: a decompositional analysis. Inj. Prev. 19 (4), 227-231. https://doi.org/10.1136/injuryprev-2012-040594.

Zuckerman, M., 1994. Behavioral Expressions and Biological Bases of Sensation Seeking. Cambridge University Press, New York. 